\title{
Rapid diagnosis of experimental meningitis by bacterial heat production in cerebrospinal fluid
}

\author{
Andrej Trampuz ${ }^{\dagger 1,2}$, Andrea Steinhuber ${ }^{\dagger 2}$, Matthias Wittwer ${ }^{3}$ and \\ Stephen L Leib*3
}

Address: ${ }^{1}$ Division of Infectious Diseases \& Hospital Epidemiology, Department of Internal Medicine, University Hospital Basel, Basel, Switzerland, 2Infectious Diseases Research Laboratory, Department of Biomedicine, University Hospital Basel, Basel, Switzerland and ${ }^{3}$ Institute for Infectious Diseases, University of Bern, Bern, Switzerland

Email: Andrej Trampuz - atrampuz@uhbs.ch; Andrea Steinhuber - a.steinhuber@unibas.ch; Matthias Wittwer - matthias.wittwer@ifik.unibe.ch; Stephen L Leib* - stephen.leib@ifik.unibe.ch

* Corresponding author †Equal contributors

Published: 10 October 2007

BMC Infectious Diseases 2007, 7:116 doi:10.1186/1471-2334-7-116
Received: 4 June 2007

Accepted: 10 October 2007

This article is available from: http://www.biomedcentral.com/I47I-2334/7/II6

(c) 2007 Trampuz et al; licensee BioMed Central Ltd.

This is an Open Access article distributed under the terms of the Creative Commons Attribution License (http://creativecommons.org/licenses/by/2.0), which permits unrestricted use, distribution, and reproduction in any medium, provided the original work is properly cited.

\begin{abstract}
Background: Calorimetry is a nonspecific technique which allows direct measurement of heat generated by biological processes in the living cell. We evaluated the potential of calorimetry for rapid detection of bacterial growth in cerebrospinal fluid (CSF) in a rat model of bacterial meningitis.
\end{abstract}

Methods: Infant rats were infected on postnatal day II by direct intracisternal injection with either Streptococcus pneumoniae, Neisseria meningitidis or Listeria monocytogenes. Control animals were injected with sterile saline or heat-inactivated S. pneumoniae. CSF was obtained at 18 hours after infection for quantitative cultures and heat flow measurement. For calorimetry, $10 \mu \mathrm{l}$ and I $\mu \mathrm{l} \mathrm{CSF}$ were inoculated in calorimetry ampoules containing $3 \mathrm{ml}$ trypticase soy broth (TSB).

Results: The mean bacterial titer $( \pm S D)$ in CSF was $1.5 \pm 0.6 \times 10^{8}$ for S. pneumoniae, $1.3 \pm 0.3 \times$ $10^{6}$ for $N$. meningitidis and $3.5 \pm 2.2 \times 10^{4}$ for L. monocytogenes. Calorimetric detection time was defined as the time until heat flow signal exceeded $10 \mu \mathrm{W}$. Heat signal was detected in $10-\mu \mathrm{l} \mathrm{CSF}$ samples from all infected animals with a mean $( \pm S D)$ detection time of $1.5 \pm 0.2$ hours for $S$. pneumoniae, $3.9 \pm 0.7$ hours for $N$. meningitidis and $9.1 \pm 0.5$ hours for $L$. monocytogenes. CSF samples from non-infected animals generated no increasing heat flow $(<10 \mu \mathrm{W})$. The total heat was the highest in S. pneumoniae ranging from 6.7 to 7.5 Joules, followed by L. monocytogenes (5.6 to 6.1 Joules) and N. meningitidis (3.5 to 4.4 Joules). The lowest detectable bacterial titer by calorimetry was 2 cfu for $S$. pneumoniae, 4 cfu for $N$. meningitidis and $7 \mathrm{cfu}$ for $L$. monocytogenes.

Conclusion: By means of calorimetry, detection times of $<4$ hours for $S$. pneumoniae and $N$. meningitidis and $<10$ hours for Listeria monocytogenes using as little as $10 \mu \mathrm{l}$ CSF were achieved. Calorimetry is a new diagnostic method allowing rapid and accurate diagnosis of bacterial meningitis from a small volume of CSF. 


\section{Background}

Bacterial meningitis requires rapid diagnosis since a delay in antimicrobial therapy results in poor outcome $[1,2]$. Examination of CSF is of paramount importance for the diagnosis of meningitis. Accordingly, once contraindications have been ruled out, a lumbar puncture is performed in patients with suspected meningitis. Immediate examination of the CSF provides valuable information. A Gram stain of CSF indicates the presence of white blood cells, their approximate differential count and whether bacteria are present. However, CSF leukocyte counts may be normal or only marginally elevated in 5 to $10 \%$ of patients, especially in early stages of the infection [3]. Gram's staining and bacterial antigen tests of the CSF permit a rapid diagnosis, but have limited sensitivity [4].

Culture of CSF for the detection of bacterial growth is the gold standard for the diagnosis of bacterial meningitis [1]. Bacterial culture has a high sensitivity but results are typically available not earlier than on the following day. Molecular methods, such as polymerase chain reaction, are increasingly used in diagnostic microbiology, but are inherently restricted to detect only the pathogens specified by the test. Therefore, a rapid and sensitive tool to detect the presence of bacteria in CSF is needed to expedite diagnosis and to improve the management of patients with meningitis. Streptococcus pneumoniae, Neisseria meningitidis and Listeria monocytogenes are the main causative organisms responsible for over $80 \%$ of all cases of bacterial meningitis in adults [5].

Calorimetry is a nonspecific technique which allows direct measurement of heat generated by biological processes in the living cell. Microorganisms are reported to produce on average 1-3 pW heat per cell [6]. The exponential replication of microorganisms results in thermal changes over time that can be documented in real-time (i.e. heat power-time curve) by calorimetry. The current calorimeter can detect heat differences of less than $1 \mu \mathrm{W}$, which occur within minutes to hours if microorganisms grow exponentially in an appropriate medium. The detection time depends on the initial number of organisms, their replication rate and heat production per cell.

The present study was performed to demonstrate the proof of principle of calorimetry for the detection of bacterial growth in clinical samples. Here we used an infant rat model of bacterial meningitis due to infection with Streptococcus pneumoniae, Neisseria meningitidis and Listeria monocytogenes to evaluate the potential of isothermal calorimetry for rapid and sensitive detection of bacteria in small samples of CSF (i.e. 1 and $10 \mu \mathrm{L}$ ).

\section{Methods \\ Model of meningitis}

An established infant model of bacterial meningitis was used as described previously $[7,8]$. The animal studies were approved by the Animal Care and Experimentation Committee of the Canton of Bern, Switzerland, and followed National Institutes of Health guidelines for the performance of animal experiments. Briefly, nursing Wistar rats with their dams were purchased (Charles River, Germany). For each test organism, four animals (weighing $23.6 \pm 1.1 \mathrm{~g}$ ) were infected on postnatal day 11 by direct intracisternal injection of $10 \mu \mathrm{l}$ saline containing $1 \times 10^{6}$ $\mathrm{cfu} / \mathrm{ml}$ S. pneumoniae, $3 \times 10^{8} \mathrm{cfu} / \mathrm{ml} \mathrm{N}$. meningitidis and 2 $\times 10^{5} \mathrm{cfu} / \mathrm{ml}$ L. monocytogenes using a 32 -gauge needle. The pathogens investigated in the study show significant differences in virulence and pathogenicity. Therefore the number of bacteria used for infection needed to be adapted to generate reproducible infection and associated disease severity. Thus, for each pathogen the inoculum $(\mathrm{cfu} / \mathrm{ml})$ used for intracisternal infection was based on previously established disease models $[9,10]$. Control animals were injected with $10 \mu \mathrm{l}$ sterile saline $(\mathrm{n}=2)$ or sterile saline containing heat-inactivated $\left(80^{\circ} \mathrm{C}\right.$ for $\left.20 \mathrm{~min}\right)$ $S$. pneumoniae at a concentration corresponding to $2 \times 10^{8}$ $\mathrm{cfu} / \mathrm{ml}(\mathrm{n}=2)$.

\section{Infecting organisms}

Clinical isolates of S. pneumoniae (serogroup 3), N. meningitidis (type C) and L. monocytogenes (serotype 4b) were used. The infecting organisms were previously passaged through infant rats in the course of experimental studies [9]. Organisms were grown on 5\% sheep blood agar plates (Becton Dickinson, Heidelberg, Germany), cultured overnight in $10 \mathrm{ml}$ of trypticase soy broth (TSB) for S. pneumoniae and N. meningitidis, or brain heart infusion (BHI) for L. monocytogenes, diluted in fresh medium, and grown to logarithmic phase at $37^{\circ} \mathrm{C}$ in $5 \% \mathrm{CO}_{2}$. The culture broth was centrifuged for 10 minutes at 5,000 $\times \mathrm{g}$ and the pellet was resuspended in sterile saline to the desired density for intracisternal injection. The accuracy of the inoculum dose was confirmed by quantitative cultures by serial dilution for each experiment. In addition, 10-fold of serial dilutions of test organisms were prepared in concentrations from $10^{6}$ to $10^{-1} \mathrm{cfu} / \mathrm{ml}$ as quantitative standards for comparison with CSF samples.

\section{CSF sampling and processing}

At $18 \mathrm{~h}$ after infection, approx. 15 - $20 \mu \mathrm{l}$ CSF was obtained by puncture of the cisterna magna and used for quantitative cultures and calorimetry. For quantitative culture, CSF was plated in 10-fold dilutions on 5\% sheep blood agar plates (Becton Dickinson). For calorimetry, 10 $\mu \mathrm{l}$ and $1 \mu \mathrm{l} \mathrm{CSF}$ were added to $90 \mu \mathrm{l}$ and $99 \mu \mathrm{l}$ saline, respectively (total volume of $100 \mu \mathrm{l}$ ), and inoculated in calorimetry ampoules containing $3 \mathrm{ml}$ TSB. Culture broth 
with $100 \mu \mathrm{l}$ saline was used as control. Animals were sacrificed after CSF sampling with an overdose of pentobarbital (100 mg/kg intraperitoneally).

\section{Calorimetric equipment and measurements}

An isothermal calorimetry instrument (Thermal Activity Monitor, Model 3102 TAM III, TA Instruments, New Castle, DE, USA) equipped with 48 channels was used to measure the heat flow at $37^{\circ} \mathrm{C}$ precisely controlled within $0.0001^{\circ} \mathrm{C}$. The calorimetric sensitivity according to the manufacturer is $\pm 0.2 \mu \mathrm{W}$. Heat generated or absorbed was continuously measured in air-tightly sealed 4-ml glass calorimetry ampoules, containing the test or control samples; the gas phase consisted of ambient air. Ampoules were sequentially introduced into the calorimetry instrument and remained 15 minutes in the thermal equilibration position before lowering into the measurement position. Heat flow was measured for up to 48 hours at 10 $\mathrm{s}$ intervals. After the measurement was completed, the content of each calorimetry ampoule was cultured to confirm the inoculated microorganisms in infected animals or sterility of the negative controls.

\section{Analysis of calorimetric data}

Calorimetric detection time was defined as the time from insertion of the ampoule into the calorimeter until the growing culture produced an exponentially rising heat flow signal exceeding $10 \mu \mathrm{W}$. Peak heat flow was defined as the highest value of the heat power-time curve. Total heat was determined by integration of the area below the heat flow-time curve. Data analysis was accomplished using the manufacturer's software (TAM Assistant, TA Instruments, New Castle, DE, USA) and Origin 7.5 (Microcal, Northampton, MA, USA).

\section{Results}

\section{Bacterial meningitis in infant rats}

At 18 hours after intracisternal injection, all infected rats suffered from meningitis as evidenced by lethargy, dimin- ished weight gain and positive CSF cultures. Table 1 shows the bacterial density in CSF at 18 hours after infection. In control animals, injected with sterile saline or heat-inactivated bacteria, no signs of meningitis were observed at $18 \mathrm{~h}$ after infection and no bacteria grew in CSF cultures.

\section{Heat power-time curves from CSF and standard bacterial dilutions}

Heat signal was detected in CSF samples from all infected animals, whereas those from non-infected animals generated no detectable heat $(<10 \mu \mathrm{W})$. Figure 1 shows heat power-time curves from 10- $\mu$ l CSF samples (bold lines) in correlation with heat produced by serial 10 -fold bacterial dilutions ranging from $10^{6}$ to $10^{-1} \mathrm{cfu} / \mathrm{ml}$ (grey lines). The heat curves of CSF from different individual animals infected by the same organism showed similar characteristics. For example, $S$. pneumoniae showed a discrete initial peak heat flow at $40 \mu \mathrm{W}$, followed by a second peak at about $350 \mu \mathrm{W}$. N. meningitidis demonstrated a clear initial peak, followed by a higher peak at approximately $80 \mu \mathrm{W}$. Replicates of $L$. monocytogenes showed three peaks, at $\approx 80$ $\mu \mathrm{W}, \approx 300 \mu \mathrm{W}$ and $\approx 350 \mu \mathrm{W}$. The shape of the curves was dependent on the growth medium in the calorimetry ampoule, but independent from the initial bacterial concentration (data not shown). The bacterial titer in CSF at 18 hours after infection correlated with the standard dilutions for S. pneumoniae, but was two orders of magnitude lower for $N$. meningitidis and three orders of magnitude lower for $L$. monocytogenes. The total heat was the highest in S. pneumoniae ranging from 6.7 to 7.5 Joules, followed by L. monocytogenes (5.6 to 6.1 Joules) and $N$. meningitidis (3.5 to 4.4 Joules). CSF from animals that had been injected with heat-killed bacteria resulted in power-time curves very similar to those of the medium-controls. The values always remained below the $10 \mu \mathrm{W}$ positivity limit and continuously decreased towards baseline.

Table I: Bacterial concentration and calorimetric detection time of I $\mu$ l and $10 \mu \mathrm{I} \mathrm{CSF} \mathrm{punctured} \mathrm{I8} \mathrm{h} \mathrm{after} \mathrm{intracisternal} \mathrm{injection} \mathrm{of}$ bacteria (infected cases) or sterile fluid (controls). Calorimetric detection time is defined by the time from insertion of the ampoule into the calorimeter until the heat flow exceeded $10 \mu \mathrm{W}$. Data represent mean values \pm SD.

\begin{tabular}{|c|c|c|c|c|}
\hline \multirow[t]{2}{*}{ Intracisternal injection (No. of animals) } & \multirow{2}{*}{$\begin{array}{l}\text { Bacterial titer in CSF } \\
(\mathrm{cfu} / \mathrm{ml})\end{array}$} & \multicolumn{2}{|c|}{ Calorimetric detection time $(h)^{a}$} & \multirow[t]{2}{*}{ Peak heat flow $(\mu \mathrm{W})^{\mathrm{b}}$} \\
\hline & & $10 \mu \mathrm{l} \mathrm{CSF}$ & I $\mu$ l CSF & \\
\hline S. pneumoniae $(n=4)$ & $1.5 \pm 0.6 \times 10^{8}$ & $1.5 \pm 0.2$ & $2.8 \pm 0.3$ & $342 \pm 29$ \\
\hline N. meningitidis $(n=4)$ & $1.3 \pm 0.3 \times 10^{6}$ & $3.9 \pm 0.7$ & $5.5 \pm 1.1$ & $75 \pm 24$ \\
\hline L. monocytogenes $(n=4)$ & $3.5 \pm 2.2 \times 10^{4}$ & $9.1 \pm 0.5$ & $13.0 \pm 1.0$ & $340 \pm 15$ \\
\hline Heat-inactivated S. pneumoniae $(n=2)$ & No growth & Negative & Negative & $<10$ \\
\hline Saline control $(n=2)$ & No growth & Negative & Negative & $<10$ \\
\hline
\end{tabular}

NOTE. CSF, cerebrospinal fluid.

a Defined as the time from the start of measurement until the detected heat flow exceeds $10 \mu \mathrm{W}$.

b Peak heat flow was the highest value of the heat power-time curve. 

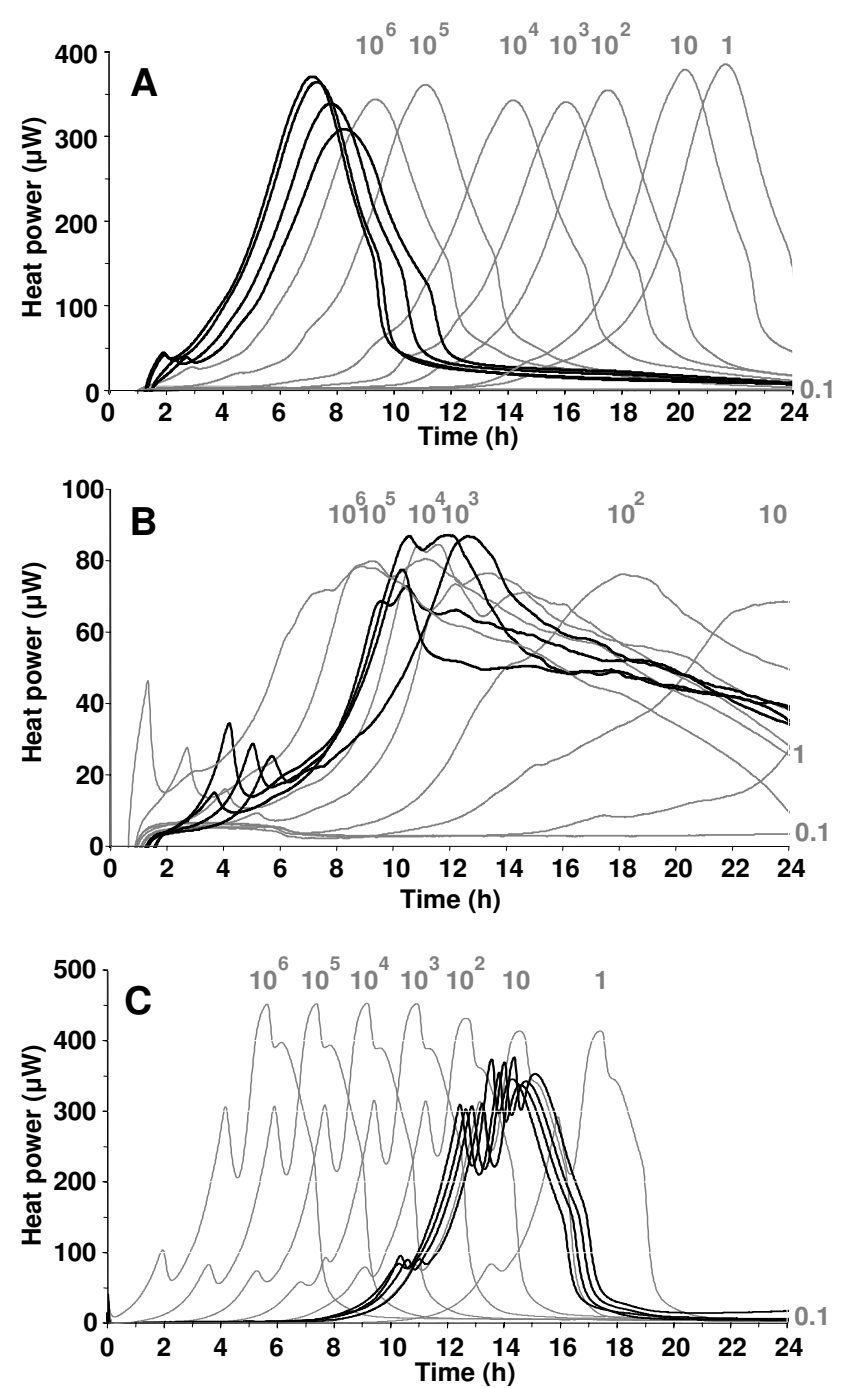

Figure I

Heat power-time curves for S. pneumoniae (A), N. meningitidis $(B)$ and $L$. monocytogenes (C). Black lines represent heat produced from I0- $\mu \mathrm{I}$ CSF samples drawn at 18 hours after infection from four rats per group and bacterial species. The corresponding mean $( \pm S D)$ bacterial titer were $1.5 \pm 0.6 \times$ $10^{8} \mathrm{cfu} / \mathrm{ml}$ for $S$. pneumoniae, $1.3 \pm 0.3 \times 10^{6} \mathrm{cfu} / \mathrm{ml}$ for $N$. meningitidis and $3.5 \pm 2.2 \times 10^{4} \mathrm{cfu} / \mathrm{ml}$ for $L$. monocytogenes. CSF from non-infected rats (controls) produced no heat. Grey lines represent serial 10 -fold bacterial dilutions from $10^{6}$ to $10^{-1} \mathrm{cfu} / \mathrm{ml}$.

\section{Calorimetric detection time from CSF}

Table 1 summarizes the calorimetric detection times for the different pathogens generated from $10 \mu \mathrm{l}$ and $1 \mu \mathrm{l}$ of CSF. The detection time is defined by the time elapsed from the start of measurement until the detected heat flow exceeds $10 \mu \mathrm{W}$. In 10- $\mu$ l CSF samples, S. pneumoniae was detected after a mean \pm SD of $1.5 \pm 0.2$ hours, followed by
N. meningitidis after $3.9 \pm 0.7$ hours and by L. monocytogenes after $9.1 \pm 0.5$ hours.

\section{Calorimetric detection limit}

As determined from standard bacterial dilutions by linear regression analysis, the lowest detectable bacterial titer by calorimetry was $2 \mathrm{cfu}$ for $S$. pneumoniae, $4 \mathrm{cfu}$ for N. meningitidis and $7 \mathrm{cfu}$ for L. monocytogenes using TSB (Figure 2). The lowest bacterial titer was detected after 15.2, 19.7 and 12.2 hours of incubation, respectively.

\section{Influence of media on calorimetric detection time}

In addition to TSB, BHI was used as an alternative growth medium for the detection of S. pneumoniae and L. monocytogenes. CSF drawn from animals was split into identical volumes of $10 \mu \mathrm{l}$ and inoculated in parallel in calorimetry ampoules containing TSB or BHI. The mean detection time $( \pm$ SD) in TSB was $1.71 \pm 0.37$ hours shorter for $S$. pneumoniae and $1.17 \pm 0.87$ hours shorter for L. monocytogenes compared to BHI. Similarly, the peak heat flow of CSF in TSB was $174 \mu \mathrm{W}$ higher for S. pneumoniae and 69 $\mu \mathrm{W}$ higher for L. monocytogenes as compared to BHI.

\section{Discussion}

Bacterial meningitis is a medical emergency situation associated with a substantial morbidity and mortality. Despite appropriate antibiotic therapy recent studies document a mortality rate of up to $30 \%$ and the occurrence of permanent sequelae due to neuronal injury in up to $50 \%$ of the survivors $[1,2,11]$. A number of studies suggest an association between adverse clinical outcome of bacterial meningitis and the time until initiation of antibiotic therapy after presentation $[1,2,12,13]$. Thus, rapid diagnosis and start of antibiotic therapy should be a major therapeutic goal for physicians treating patients with bacterial meningitis [1]. The ongoing search for alternative methods to diagnose bacterial meningitis more rapidly, such as polymerase chain reaction based detection of bacterial DNA and RNA or latex agglutination tests in CSF, and the variety of published clinical prediction rules and algorithms of clinical and CSF parameters are testimony to the fact that the available diagnostic tools are still unsatisfactory in the clinical situation [14].

Calorimetry has been widely used in biology, chemistry, pharmacology, biotechnology and ecology because of its high sensitivity, accuracy and simplicity [15]. However, its clinical application was previously hindered by insufficiently sensitive equipment, low throughput capacity and the lack of appropriate software. In past years, the technology improved and highly sensitive instruments are now available, capable to detect temperature differences of $<10^{-6}{ }^{\circ} \mathrm{C}[16]$. The exponential increase of the heat signal reflects the exponential increase in bacterial numbers during the logarithmic growth phase [17]. In a recent study 

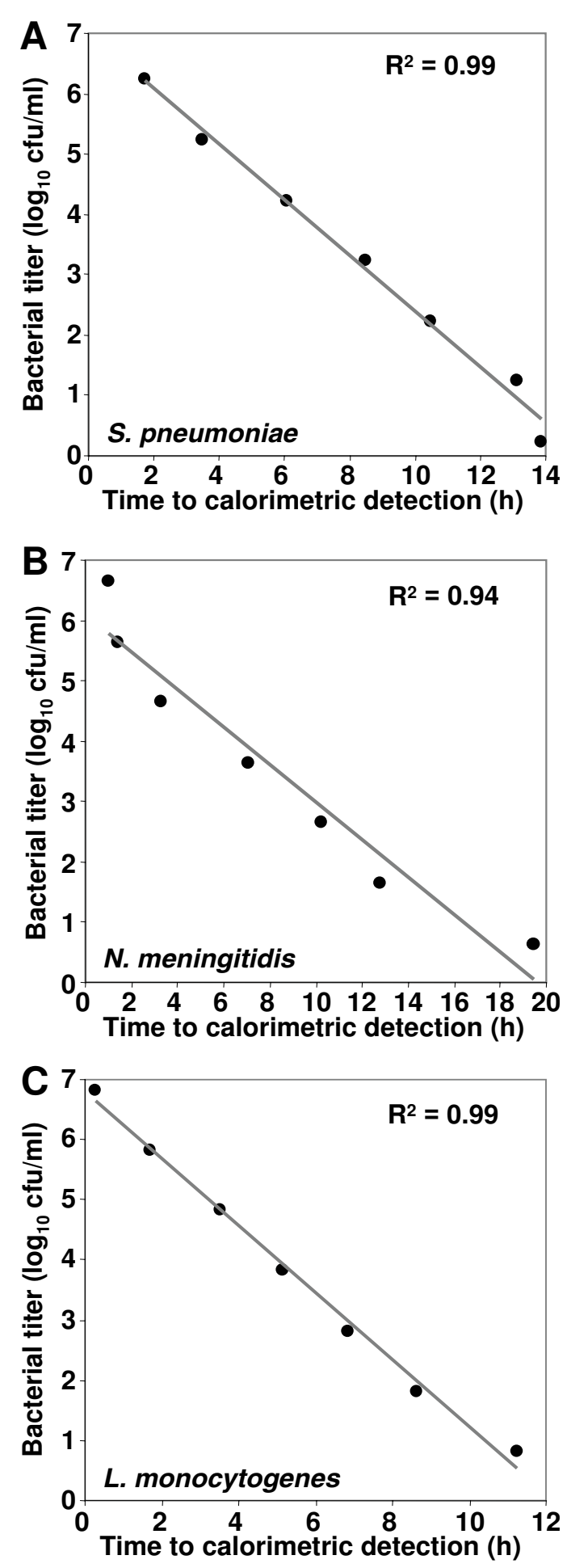

\section{Figure 2}

Correlation between the time to calorimetric detection and initial bacterial titer based on serial 10 -fold dilutions ranging from $10^{6}$ to $10^{-1} \mathrm{cfu} / \mathrm{ml}$ of (A) S. pneumoniae, (B) N. meningitidis, and (C) L. monocytogenes. $R^{2}$ denotes the coefficient of determination using simple linear regression. the potential of calorimetry to detect contaminated platelets concentrates was evaluated [18]. The present report is the first about the application of calorimetry as diagnostic tool in clinical samples, e.g. CSF in bacterial meningitis.

The detection principle relies on the heat generation of viable, replicating bacteria from CSF in culture medium that is continuously measured by isothermal calorimetry. The sensitivity of calorimetry compared to standard culture methods is equivalent when identical volumes of sample fluid are used in both methods, as the prerequisite for both detection methods is bacterial multiplication in culture. However, due to the more sensitive and continuous measurement principle of calorimetry (i.e. monitoring of heat production), the detection time is significantly shorter than with conventional cultures, which is based on detection of growth on agar plates or in broth.

All infected animals in the present study were diagnosed by calorimetric analysis of punctured CSF samples within hours and with a high discriminative power compared to sterile inflammation or medium controls. The present data are in agreement with the recent finding that the mode of growth observed in bacteria during invasive tissue infection, e.g. growth in cerebrospinal fluid, differs significantly from bacterial growth in liquid medium [19]. The metabolic activity of inflammatory cells in CSF, mainly leukocytes, did not interfere with the increasing heat signal of the multiplying bacteria. For all tested bacterial species the detection time, corresponding to the time until a threshold level of $10 \mu \mathrm{W}$ was reached, was dependent on the concentration of bacteria. Initial numbers of less than $10 \mathrm{cfu}$ of organisms per calorimetric ampoule could be detected.

\section{Conclusion}

In the present approach, detection times of $<4$ hours for $S$. pneumoniae and $N$. meningitidis and $<10$ hours for Listeria monocytogenes using as little as $10 \mu \mathrm{l} \mathrm{CSF}$ were achieved. In the clinical situation larger volumes of CSF are usually available from patients, which may further shorten the detection time. This method is particularly well suited in situations where CSF volumes are limited (e.g. in newborns and infants). Calorimetric detection of bacterial growth may thus provide an accurate tool to rapidly diagnose bacterial meningitis with the benefit of low labor intensiveness, few handling steps, potential of complete automation, and minimal contamination and biohazard risk due to the closed ampoule system.

In addition, we found that TSB is an appropriate medium for rapid detection of all tested microorganisms in this study. The differences in the power-time curves of L. monocytogenes after (CSF) or without (standard curves) passages through the animal could be due to adaptation of the 
pathogen that may be associated with a prolonged lag phases and longer generation times.

This study demonstrates that calorimetry is a promising novel approach for rapid and accurate diagnosis of bacterial meningitis, allowing detection of multiplying bacteria in small volumes of CSF $(1-10 \mu \mathrm{l})$ within hours.

\author{
Abbreviations \\ Cerebrospinal fluid - CSF \\ Trypticase soy broth - TSB \\ Brain heart infusion - BHI \\ Standard deviation - SD
}

\section{Competing interests}

The author(s) declare that they have no competing interests.

\section{Authors' contributions}

All authors read and approved the final manuscript. AT, AS and SLL contributed equally for study design, coordination, interpretation of results and writing of the manuscript. AS, MW and SLL participated in data collection and experimental procedures.

\section{Acknowledgements}

The authors would like to thank Jürg Kummer and Kevin Oberson, Institute for Infectious Diseases, University of Bern, Switzerland for excellent technical assistance. We thank Alma U. Daniels, Laboratory for Orthopedic Biomechanics, University of Basel, Switzerland, for providing access to the calorimeter.

This work was supported by grants obtained by the Swiss National Foundation (632-66057.0I), the Velux Foundation, the Stanley Thomas Johnson Foundation and the Gebert Rüf Stiftung (GRS-070/06).

Part of this work has been presented at the 17th European Congress of Clinical Microbiology and Infectious Diseases and 25th International Congress of Chemotherapy; Munich/Germany, 3I March - 3 April 2007.

\section{References}

I. Aronin SI, Peduzzi P, Quagliarello VJ: Community-acquired bacterial meningitis: risk stratification for adverse clinical outcome and effect of antibiotic timing. Ann Intern Med 1998, 1 29:862-869.

2. Proulx N, Frechette D, Toye B, Chan J, Kravcik S: Delays in the administration of antibiotics are associated with mortality from adult acute bacterial meningitis. QJM 2005, 98:29I-298.

3. van de Beek D, de Gans J, Spanjaard L, Weisfelt M, Reitsma JB, Vermeulen $\mathrm{M}$ : Clinical features and prognostic factors in adults with bacterial meningitis. N EnglJ Med 2004, 35 I: I 849-1859.

4. Hussein AS, Shafran SD: Acute bacterial meningitis in adults. A I 2-year review. Medicine (Baltimore) 2000, 79:360-368.

5. van de Beek D, de Gans J, Tunkel AR, Wijdicks EF: Communityacquired bacterial meningitis in adults. N Engl J Med 2006, 354:44-53.

6. James AM: Thermal and energetic studies of cellular biological systems Edited by: James AM. Bristol, UK, Wright; 1987.
7. Bifrare YD, Kummer J, Joss P, Täuber MG, Leib SL: Brain-derived neurotrophic factor protects against multiple forms of brain injury in bacterial meningitis. J Infect Dis 2005, 191 1:40-45.

8. Leib SL, Clements JM, Lindberg RL, Heimgartner C, Loeffler JM, Pfister LA, Täuber MG, Leppert D: Inhibition of matrix metalloproteinases and tumour necrosis factor alpha converting enzyme as adjuvant therapy in pneumococcal meningitis. Brain 200I, I 24:1734-1742.

9. Sellner J, Leib SL: In bacterial meningitis cortical brain damage is associated with changes in parenchymal MMP-9/TIMP-I ratio and increased collagen type IV degradation. Neurobiol Dis 2006, $21: 647-656$.

10. Remer KA, Jungi TW, Fatzer R, Täuber MG, Leib SL: Nitric oxide is protective in listeric meningoencephalitis of rats. Infect Immun 200I, 69:4086-4093.

II. Weisfelt M, van de BD, Spanjaard L, Reitsma JB, de Gans J: Clinical features, complications, and outcome in adults with pneumococcal meningitis: a prospective case series. Lancet Neurol 2006, 5: 123-129.

12. Miner JR, Heegaard W, Mapes A, Biros M: Presentation, time to antibiotics, and mortality of patients with bacterial meningitis at an urban county medical center. J Emerg Med 200I, 21:387-392.

13. Bryan CS, Reynolds KL, Crout L: Promptness of antibiotic therapy in acute bacterial meningitis. Ann Emerg Med 1986, I 5:544-547.

14. Nigrovic LE, Kuppermann N, Macias CG, Cannavino CR, Moro-Sutherland DM, Schremmer RD, Schwab SH, Agrawal D, Mansour KM, Bennett JE, Katsogridakis YL, Mohseni MM, Bulloch B, Steele DW, Kaplan RL, Herman MI, Bandyopadhyay S, Dayan P, Truong UT, Wang VJ, Bonsu BK, Chapman JL, Kanegaye JT, Malley R: Clinical prediction rule for identifying children with cerebrospinal fluid pleocytosis at very low risk of bacterial meningitis. JAMA 2007, 297:52-60.

15. Wadso I: Isothermal microcalorimetry in applied biology. Thermochim Acta 2002, 394:305-3II.

16. O'Neill MA, Gaisford S, Beezer AE, Skaria CV, Sears P: A comparison of the performance of calorimeters. Application of a test and reference reaction. I Therm Anal Cal 2006, 84:30I-306.

17. Beezer AE: Biological microcalorimetry Edited by: Beezer AE. London, UK, Academic Press; 1980.

18. Trampuz A, Salzmann S, Antheaume J, Daniels AU: Microcalorimetry - a novel method for detection of microbial contamination in platelet products. Transfusion 2007, (in press):.

19. Oggioni MR, Trappetti C, Kadioglu A, Cassone M, lannelli F, Ricci S, Andrew PW, Pozzi G: Switch from planktonic to sessile life: a major event in pneumococcal pathogenesis. Mol Microbiol 2006, 61:1196-1210.

\section{Pre-publication history}

The pre-publication history for this paper can be accessed here:

http://www.biomedcentral.com/1471-2334/7/116/pre pub

Publish with Biomed Central and every scientist can read your work free of charge

"BioMed Central will be the most significant development for disseminating the results of biomedical research in our lifetime. "

Sir Paul Nurse, Cancer Research UK

Your research papers will be:

- available free of charge to the entire biomedical community

- peer reviewed and published immediately upon acceptance

- cited in PubMed and archived on PubMed Central

- yours - you keep the copyright 